\title{
Quantitative computed tomography measurements of emphysema for diagnosing asthma-chronic obstructive pulmonary disease overlap syndrome
}

\author{
This article was published in the following Dove Press journal: \\ International Journal of COPD \\ 6 May 2016 \\ Number of times this article has been viewed
}

\section{Mengshuang Xie \\ Wei Wang \\ Shuang Dou \\ Liwei Cui \\ Wei Xiao}

Department of Pulmonary Medicine, Qilu Hospital, Shandong University, Jinan, People's Republic of China
Correspondence: Wei Xiao

Department of Pulmonary Medicine,

Qilu Hospital, Shandong University,

107 Wenhua West Road, Jinan 2500I2,

People's Republic of China

$\mathrm{Tel}+8653182166294$

Email xiaowei4226@I63.com
Background: The diagnostic criteria of asthma-COPD overlap syndrome (ACOS) are controversial. Emphysema is characteristic of COPD and usually does not exist in typical asthma patients. Emphysema in patients with asthma suggests the coexistence of COPD. Quantitative computed tomography (CT) allows repeated evaluation of emphysema noninvasively. We investigated the value of quantitative CT measurements of emphysema in the diagnosis of ACOS.

Methods: This study included 404 participants; 151 asthma patients, 125 COPD patients, and 128 normal control subjects. All the participants underwent pulmonary function tests and a highresolution CT scan. Emphysema measurements were taken with an Airway Inspector software. The asthma patients were divided into high and low emphysema index (EI) groups based on the percentage of low attenuation areas less than -950 Hounsfield units. The characteristics of asthma patients with high EI were compared with those having low EI or COPD.

Results: The normal value of percentage of low attenuation areas less than -950 Hounsfield units in Chinese aged $>40$ years was $2.79 \% \pm 2.37 \%$. COPD patients indicated more severe emphysema and more upper-zone-predominant distribution of emphysema than asthma patients or controls. Thirty-two (21.2\%) of the 151 asthma patients had high EI. Compared with asthma patients with low EI, those with high EI were significantly older, more likely to be male, had more pack-years of smoking, had more upper-zone-predominant distribution of emphysema, and had greater airflow limitation. There were no significant differences in sex ratios, pack-years of smoking, airflow limitation, or emphysema distribution between asthma patients with high EI and COPD patients. A greater number of acute exacerbations were seen in asthma patients with high EI compared with those with low EI or COPD.

Conclusion: Asthma patients with high EI fulfill the features of ACOS, as described in the Global Initiative for Asthma and Global Initiative for Chronic Obstructive Lung Disease guidelines. Quantitative CT measurements of emphysema may help in diagnosing ACOS.

Keywords: COPD, asthma, quantitative CT, emphysema, overlap syndrome

\section{Introduction}

Asthma and COPD are the leading causes of morbidity and mortality worldwide and are associated with significant economic and social burdens. ${ }^{1,2}$ They are traditionally viewed as distinct clinical entities. Asthma is typically recognized as an allergic disease, often affecting children and young adults, characterized by reversible airflow 
obstruction and favorable prognosis. In contrast, COPD is typically caused by tobacco smoking, usually affects adults aged $>40$ years, and displays persistent airflow obstruction, resulting in progressive decline in lung function and premature death. ${ }^{3}$ However, some patients may have clinical features of both asthma and COPD, which is called the asthma-COPD overlap syndrome (ACOS). ${ }^{4}$ Compared with asthma or COPD alone, ACOS is associated with more frequent exacerbations and hospitalizations and a higher overall health care burden and mortality. ${ }^{5-8}$ Therefore, making an accurate diagnosis of ACOS is very important.

Although ACOS has been accepted as a distinct disease by Global Initiative for Asthma (GINA) and Global Initiative for Chronic Obstructive Lung Disease (GOLD), the diagnostic criteria remain unclear. ${ }^{4}$ To date, there is little established evidence regarding its diagnosis and treatment, as ACOS patients have been excluded from clinical trials for both asthma and COPD. ${ }^{4}$ Therefore, differentiating ACOS from asthma and COPD is challenging.

Emphysema is an important pathological feature of COPD. It is defined as "abnormal permanent enlargement of air spaces distal to terminal bronchioles, accompanied by destruction of their walls without obvious fibrosis". . Varying extents of emphysema and small airway disease lead to persistent airflow obstruction in COPD.

Unlike COPD, asthma was considered to be predominantly an airway disease, generally without destruction of lung parenchyma (emphysema). ${ }^{10}$ However, previous studies have shown that some asthma patients also had signs of emphysema as shown on computed tomography (CT) of the chest. ${ }^{11}$ Gelb et al ${ }^{12}$ even found mild emphysema on histopathology of nonsmoking patients with asthma. These asthma patients have signs of emphysema, suggesting the coexistence of COPD. Evaluating the extent of emphysema may identify asthma patients with coexisting COPD, which may facilitate the diagnosis of ACOS.

Quantitative CT is a promising technique, because it has made repeated and noninvasive measurements of structural changes in the lungs possible. ${ }^{13,14}$ Emphysema is characterized by areas of reduced attenuation coefficients in the lungs on CT. ${ }^{15}$ The severity of emphysema is generally quantified as the percentage of "low attenuation area" (LAA) in the lungs with Hounsfield units (HU) less than a specific threshold (eg, -950 HU; \%LAA-950). ${ }^{16}$ Previous studies have demonstrated that the measurements of emphysema in quantitative CT correlate well with the visual scoring systems and pathology measurements. ${ }^{13,16}$
There is little evidence on the diagnostic value of quantitative CT measurements of emphysema for ACOS. We hypothesized that quantitative CT measurement of emphysema may detect asthma patients with signs of emphysema and those patients may fulfill the characteristics of ACOS. We aimed to: 1) establish the normal range of \%LAA-950 in Chinese patients aged $>40$ years; 2 ) compare the quantitative $\mathrm{CT}$ measurements and emphysema distribution between normal, asthma, and COPD patients; 3 ) investigate the value of quantitative CT measurements of emphysema in the diagnosis of ACOS; and 4) investigate the predictors of high emphysema index (EI) in patients with asthma.

\section{Methods \\ Subjects}

This study is part of a prospective observational study being performed at Qilu Hospital, People's Republic of China. We recruited 404 participants: 125 with COPD, 151 with asthma, and 128 normal controls. All the participants were mainland Chinese, aged between 40 and 85 years, who presented to the Qilu Hospital between July 2013 and November 2015.

On the basis of GINA guidelines, asthma was diagnosed as respiratory symptoms such as wheezing and shortness of breath varying over time and in intensity, together with variable expiratory airflow limitation (post-bronchodilator [BD] improvement in forced expiratory volume in 1 second [ $\mathrm{FEV}_{1}$ ] $>12 \%$ and $>200 \mathrm{~mL}$ or average daily diurnal peak expiratory flow variability $>10 \%$ over 2 weeks). ${ }^{17}$ Those asthma patients with persistent airflow limitation (the potential ACOS patients) were also enrolled in the asthma group. Patients were diagnosed with COPD based on $>10$ pack-years smoking history or confirmed noxious gas or particle exposure, physical examination, respiratory symptoms, and persistent airflow limitation (post-BD FEV ${ }_{1}$ /forced vital capacity $[\mathrm{FVC}]<0.70$ ), according to the GOLD guidelines. ${ }^{18}$ Patients with asthma syndrome or history of asthma were excluded from the COPD group. Controls were recruited from healthy nonsmokers aged between 40 and 85 years with normal spirometry ( $\mathrm{FEV}_{1}$ $\geq 80 \%$ predicted and $\mathrm{FEV}_{1} / \mathrm{FVC} \geq 0.7$ ) who underwent chest $\mathrm{CT}$ for health examination. Those who had a history of lung disease or pulmonary nodules $>1 \mathrm{~cm}$ in high-resolution CT (HRCT) were excluded from the normal control group.

We excluded patients with: 1) acute exacerbation within the past 6 weeks; 2) other lung diseases such as extensive bronchiectasis, cystic fibrosis, interstitial lung disease, lung cancer, or infectious lung disease; 3) pulmonary masses $>3 \mathrm{~cm}$ on chest $\mathrm{CT}$; 4) severe comorbid conditions, such as congestive heart failure, severe hepatic and renal 
dysfunction, cancer, malnutrition, or severe anemia; and 5) any cognitive disorder.

All participants completed standardized questionnaires and underwent pulmonary function tests (PFTs) and HRCT on the same day. Demographic characteristics and acute exacerbations of the previous year were recorded.

The study was approved by the Ethics Committee of Qilu Hospital of Shandong University (No 2015091). All participants gave written informed consent to participate in the study.

\section{PFTs}

After the patients inhaled a short-acting $\beta$-agonist for 15 minutes; PFTs were performed on a computerized spirometer (MasterScreen, Jaeger, Hoechberg, Germany) according to the American Thoracic Society and the European Respiratory Society (ATS/ERS) recommendations. ${ }^{19}$ Basic information, including age, height, weight, and spirometry data (FEV1.0, FVC, FEV1.0/FVC, FVC, and vital capacity $[\mathrm{VC}]$ ), were collected. Post-BD $\mathrm{FEV}_{1} / \mathrm{FVC}<0.70$ was termed as airflow limitation. ${ }^{18}$

\section{HRCT scanning}

Chest HRCT was performed at maximal inspiration with the participants in supine position using a 64-slice spiral CT scanner (SOMATOM Definition AS, Siemens Healthcare, Erlangen, Germany). Tube voltage was $120 \mathrm{kV}$ and tube current varied by automatic regulation, based on slice location and participants' body habitus. The exposure time was 0.5 second and the matrix size was $512 \times 512$ pixels. Images were contiguously reconstructed with a $1 \mathrm{~mm}$ slice thickness (with $0.625 \mathrm{~mm}$ overlapping), using a standard algorithm.

\section{CT measurements of emphysema}

All CT images were automatically analyzed by Airway Inspector software (Surgical Planning Laboratory at Brigham and Women's Hospital, Boston, MA, USA). The extent of emphysema was measured by the density mask and percentile point methods. For the density mask method, emphysema was quantified by percentage of lung voxels with CT attenuation value below -950 HU (\%LAA-950) or $-910 \mathrm{HU}$ (\%LAA-910) on the inspiratory images. For the percentile point method, emphysema was measured as mean lung attenuation at the 10th or 15 th percentile on lung attenuation curve (LP10A, LP15A). ${ }^{16,20}$ Previous studies have shown that \%LAA-950 has the strongest correlation with emphysema at both the macroscopic and microscopic levels among all the emphysema indicators measured by quantitative CT. ${ }^{21,22} \%$ LAA-950 is also the most common used parameter in previous studies. ${ }^{14,16,20}$ For this reason, $\%$ LAA-950 was selected as the major indicator of pulmonary emphysema and defined it as "EI".

In order to study the distributions of emphysema, the lungs were divided into three regions with equal volume: upper, middle, and lower. The EI of each region was calculated. The distributions of EI were classified as: 1) upperlung-zone predominance (ULP): the EI of upper lung zone was higher than that of middle and lower lung zones, and the difference between the upper and lower lung zones was $>10 \%$; 2) lower-lung-zone predominance: the EI of lower lung zone was higher than that of middle and upper lung zones, and the difference between the upper and lower lung zones was $>10 \%$; and 3 ) middle/homogeneous distribution: the EI of middle lung zone was higher than both the upper and the lower lung zones or the difference between the upper and lower lung zones was $<10 \%$. $^{23,24}$ The relative amount of ULP (per ULP) in groups was also calculated.

\section{Statistical analysis}

Statistical analyses were performed using SPSS version 19.0 (IBM Corporation, Armonk, NY, USA). A $P$-value of $<0.05$ was deemed statistically significant. Demographic and clinical characteristics of all subjects were summarized descriptively. Quantitative data were expressed as mean \pm standard deviation (SD). Quantitative data of asthma, COPD, and control participants were compared using the Kruskal-Wallis test followed by pairwise multiple comparisons with Bonferroni correction. The sex ratio and distributions of emphysema were compared using chi-square test. The Mann-Whitney $U$ test was used to assess the differences between quantitative variables. Binary logistic regression models were used to identify predictive factors of the presence of high EI in asthma patients by a stepwise method, with a probability value for entry $(P=0.05)$ and removal $(P=0.10)$.

\section{Results \\ Participants' characteristics}

We included 404 participants; 151 asthma, 125 COPD, and 128 control participants. The clinical characteristics of each group are shown in Table 1. Compared with asthma and control participants, those with COPD were older $(P<0.001)$, had greater pack-years of smoking $(P<0.001)$, and had a lower body mass index (BMI) $(P<0.05)$. The pulmonary function parameters, including FEV1.0, FEV1.0/FVC, FVC, and VC, were worse in COPD patients compared with those with asthma $(P<0.001)$. There was no significant difference in acute exacerbations per year between asthma and COPD patients $(P=0.436)$. 
Table I Characteristics of participants

\begin{tabular}{|c|c|c|c|c|}
\hline Characteristics & Controls $(n=128)$ & Asthma $(n=15 I)$ & COPD $(n=125)$ & $P$-value \\
\hline Age, years & $59.8 \pm 8.5$ & $58.2 \pm 9.4^{* * *}$ & $65.8 \pm 9.3^{*, \#}$ & $<0.00 \mathrm{I}^{\mathrm{a}}$ \\
\hline Sex, female/male & $49 / 79$ & $81 / 70$ & $32 / 93$ & $<0.00 \mathrm{I}^{\mathrm{b}}$ \\
\hline $\mathrm{BMI}, \mathrm{kg} / \mathrm{m}^{2}$ & $24.3 \pm 3.3$ & $25.5 \pm 3.9 * *$ & $22.6 \pm 4.5^{*, \#}$ & $<0.00 \mathrm{I}^{\mathrm{a}}$ \\
\hline Smoking, pack-years & 0 & $12.1 \pm 2 \mid .8^{*}$ & $34.5 \pm 26.6$ *\#\# & $<0.00 \mathrm{I}^{\mathrm{a}}$ \\
\hline Current/former/never smoker & $0 / 0 / 128$ & $28 / 23 / 100$ & $57 / 49 / 19$ & $<0.00 \mathrm{I}^{\mathrm{b}}$ \\
\hline Acute exacerbations & NA & $1.1 \pm 0.8$ & $1.2 \pm 0.9$ & $0.436^{c}$ \\
\hline \multicolumn{5}{|l|}{ Postbronchodilator } \\
\hline $\mathrm{FEV}_{1} \%$ predicted & $100.9 \pm 13.2$ & $65.1 \pm 22.5^{*}$ & $44.3 \pm 18.6^{*, \#}$ & $<0.00 \mathrm{I}^{\mathrm{a}}$ \\
\hline FVC\% predicted & $103.4 \pm 13.9$ & $88.5 \pm 18.1^{*}$ & $73.6 \pm 17.5^{* \# \#}$ & $<0.00 I^{\mathrm{a}}$ \\
\hline VC\% predicted & $103.9 \pm 13.2$ & $88.9 \pm 17.1^{*}$ & $76.0 \pm 16.2^{\text {*.\# }}$ & $<0.00 I^{\mathrm{a}}$ \\
\hline $\mathrm{FEV}_{1} / \mathrm{FVC} \%$ & $81.3 \pm 5.2$ & $60.5 \pm 13.9 *$ & $48.1 \pm 12.2^{* \# \#}$ & $<0.00 I^{\mathrm{a}}$ \\
\hline \multicolumn{5}{|l|}{ Response to $\beta_{2}$-agonist } \\
\hline$\Delta \mathrm{FEV}_{1}, \mathrm{~L}$ & NA & $0.305 \pm 0.033$ & $0.143 \pm 0.009$ & $<0.00 \mathrm{I}^{\mathrm{c}}$ \\
\hline$\%$ change in $\mathrm{FEV} \%$ & NA & $22.4 \pm 16.4$ & $15.2 \pm 12.8$ & $<0.001^{c}$ \\
\hline
\end{tabular}

Notes: Data are presented as mean $\pm S D$. $* P<0.01$, ${ }^{* * P}<0.05$, ${ }^{* * *} P>0.05$ versus controls; ${ }^{*} P<0.01$ versus asthma patients. ${ }^{a}$ Analysis of Kruskal-Wallis test. ${ }^{b} A n a l y s i s$ of chi-square test. 'Analysis of Mann-Whitney $U$ test.

Abbreviations: $\mathrm{BMI}$, body mass index; $\triangle \mathrm{FEV}$, increases in forced expiratory volume in I second; $\mathrm{FEV}$, forced expiratory volume in I second; FVC, forced vital capacity; NA, not applicable; SD, standard deviation; VC, vital capacity.

\section{The normal range of El and emphysema distribution of controls}

The mean \%LAA-950, called the EI, in the controls was $2.79 \% \pm 2.37 \%$. There were no significant differences in EI between males $(2.81 \pm 1.96)$ and females $(2.75 \pm 3.2, P=0.091)$. As shown in Table 2, 65.5\% (84/182) of normal controls were middle/homogeneous distribution and only $16.4 \%(21 / 128)$ were upper-zone-predominant distribution. Participants were considered to have high EI if \%LAA-950 exceeded $9.9 \%$, corresponding to three SDs above the mean in controls. ${ }^{25}$

\section{Comparison of emphysema measurements between normal controls, COPD, and asthma patients}

Emphysema measurements of control, asthma, and COPD participants are shown in Table 2. COPD patients had significantly higher EI $(15.84 \pm 11.90)$ than patients with asthma $(6.19 \pm 6.79, P<0.001)$ and controls $(2.79 \pm 2.37$, $P<0.001)$. Other emphysema measurements including \%LAA-910, LP10A, and LP15A were also higher in COPD patients than in patients with asthma $(P<0.001)$ and controls

Table 2 Emphysema measurements of asthma, COPD, and control participants

\begin{tabular}{|c|c|c|c|c|}
\hline & Controls $(n=128)$ & Asthma $(n=\mid 5 I)$ & COPD $(n=125)$ & $P$-value \\
\hline \%LAA-950, \% & $2.79 \pm 2.37$ & $6.19 \pm 6.79 *$ & $15.84 \pm 11.90$ *\# & $<\left.0.00\right|^{a}$ \\
\hline \%LAA-910, \% & $21.07 \pm 20.06$ & $26.20 \pm 18.78 * *$ & $40.97 \pm 17.75^{* \# \#}$ & $<0.00 I^{a}$ \\
\hline LPIOA, HU & $-914.7 \pm 23.0$ & $-924.1 \pm 32.0^{*}$ & $-954.3 \pm 25.9^{*, \#}$ & $<0.00 \mathrm{I}^{\mathrm{a}}$ \\
\hline LPI5A, HU & $-905.9 \pm 24.7$ & $-9 \mid 4.8 \pm 33.5^{*}$ & $-944.0 \pm 26.7^{* \# \#}$ & $<0.00 I^{a}$ \\
\hline Per high El, \% & 0 & 32 (21.2\%) & $83(66.4 \%)$ & $<0.00 \mathrm{I}^{\mathrm{b}}$ \\
\hline Upper zone El, \% & $2.5 \mathrm{I} \pm 2.35$ & $5.82 \pm 8.27$ & $|7.9| \pm \mid 4.68$ & NA \\
\hline Middle zone El, \% & $3.16 \pm 2.52$ & $6.42 \pm 6.64$ & $|4.72 \pm| \mid .54$ & NA \\
\hline Lower zone El, \% & $2.77 \pm 2.62$ & $6.36 \pm 7.36$ & $15.13 \pm 13.10$ & NA \\
\hline \multicolumn{5}{|c|}{ Emphysema distribution } \\
\hline ULP, n (\%) & $21(16.4)$ & $27(17.9)$ & $6 \mathrm{I}(48.8)$ & $<0.00 \mathrm{I}^{\mathrm{c}}$ \\
\hline MHE, n (\%) & $84(65.6)$ & $70(46.4)$ & $37(39.6)$ & \\
\hline LLP, n (\%) & $23(18.0)$ & $54(35.8)$ & $27(21.6)$ & \\
\hline
\end{tabular}

Notes: Data are presented as mean \pm SD or $n(\%)$. ${ }^{* P}<0.01$, ${ }^{* * P}<0.05$ versus controls; ${ }^{*} P<0.01$ versus asthma patients. ${ }^{\mathrm{a} A n a l y s i s}$ of Kruskal-Wallis test. ${ }^{\mathrm{b} A n a l y s i s}$ of Mann-Whitney $U$ test. 'Analysis of chi-square test.

Abbreviations: El, emphysema index; LAA\%-910, percentage of lung voxels with CT attenuation value below -910 HU; \%LAA-950, percentage of lung voxels with CT attenuation value below -950 HU; LLP, lower-lung-zone predominance; LPIOA, mean lung attenuation value at the I0th percentile on lung attenuation curve; LPI5A, mean lung attenuation value at the I5th percentile on lung attenuation curve; MHE, middle/homogeneous distribution; NA, not available; SD, standard deviation; ULP, upper-lungzone predominance. 
Table 3 Characteristics of asthma patients with high and low El

\begin{tabular}{|c|c|c|c|}
\hline Characteristics & Asthma with high El (n=32) & Asthma with low EI (n=I I9) & $P$-value \\
\hline Age, years & $61.3 \pm 9.4$ & $57.4 \pm 9.3$ & $0.046^{\mathrm{a}}$ \\
\hline Sex, female/male & $6 / 26$ & $75 / 44$ & $<0.00 I^{\mathrm{b}}$ \\
\hline $\mathrm{BMI}, \mathrm{kg} / \mathrm{m}^{2}$ & $22.5 \pm 3.2$ & $26.4 \pm 3.7$ & $<0.00 I^{\mathrm{a}}$ \\
\hline Smoking, pack-years & $29.8 \pm 30.0$ & $7.4 \pm 16.1$ & $<0.00 I^{a}$ \\
\hline Current/former/never smoker & $11 / 12 / 9$ & $|7 /||/ 9|$ & $<0.00 I^{\mathrm{b}}$ \\
\hline Acute exacerbations & $1.7 \pm 1.1$ & $0.9 \pm 0.7$ & $<0.00 I^{a}$ \\
\hline \multicolumn{4}{|l|}{ Postbronchodilator } \\
\hline $\mathrm{FEV}_{1} \%$ predicted & $49.5 \pm 16.7$ & $69.2 \pm 22.1$ & $<0.00 I^{a}$ \\
\hline FVC\% predicted & $84.3 \pm 16.4$ & $89.8 \pm 13.4$ & $0.097^{\mathrm{a}}$ \\
\hline VC\% predicted & $85.9 \pm 15.9$ & $89.8 \pm 17.4$ & $0.133^{\mathrm{a}}$ \\
\hline $\mathrm{FEV}_{1} / \mathrm{FVC} \%$ & $47.9 \pm 10.6$ & $63.9 \pm 12.8$ & $<0.00 I^{\mathrm{a}}$ \\
\hline \multicolumn{4}{|l|}{ Response to $\beta_{2}$-agonist } \\
\hline$\Delta \mathrm{FEV}_{1}, \mathrm{~L}$ & $0.334 \pm 0.158$ & $0.298 \pm 0.189$ & $0.17^{a}$ \\
\hline$\%$ change in $\mathrm{FEV}_{1} \%$ & $31.2 \pm 19.8$ & $20.1 \pm 14.6$ & $<0.01^{a}$ \\
\hline Percentage of airflow limitation & $100 \%$ & $60.50 \%$ & $<0.00 I^{a}$ \\
\hline$\%$ LAA-950, \% & $17.1 \pm 6.3$ & $3.3 \pm 2.7$ & $<0.00 I^{\mathrm{a}}$ \\
\hline Per ULP, \% & II (34.4) & $16(13.4)$ & $0.006^{\mathrm{b}}$ \\
\hline
\end{tabular}

Notes: Data are presented as mean \pm SD or $\mathrm{n}(\%) .{ }^{a}$ Analysis of Mann-Whitney $U$ test. ${ }^{b}$ Analysis of chi-square test.

Abbreviations: $\mathrm{BMI}$, body mass index; El, emphysema index; $\triangle \mathrm{FEV}$, increases in forced expiratory volume in I second; $\mathrm{FEV}$, forced expiratory volume in I second; FVC, forced vital capacity; \%LAA-950, percentage of lung voxels with CT attenuation value below -950 HU; SD, standard deviation; ULP, upper-lung-zone predominance; VC, vital capacity.

$(P<0.001)$. These results were consistent with the presence of emphysema in COPD patients. The emphysema distributions of asthma patients, COPD patients, and controls were significantly different $(P<0.001)$. More COPD patients showed upper-zone-predominant distribution (48.8\%) than asthma patients $(16.4 \%, P<0.001)$ and controls $(18.0 \%, P<0.001)$. The EI and other emphysema measurements (\%LAA-910, LP10A, and LP15A) of asthma patients were higher than controls $(P<0.001)$. This suggests that some asthma patients may have emphysema; therefore, we investigated the clinical characteristics of asthma patients with high EI.

\section{Comparison between asthma patients with high and low El}

We used three SDs above the mean \%LAA-950 of controls (\%LAA-950=9.9\%) as a cutoff of high EI. Out of 151 asthma patients, 32 (21.2\%) had high EI and 119 (78.8\%) had low EI. In the COPD group, 66.4\% (83/125) of patients had high EI. Table 3 shows the comparison of characteristics between asthma patients with high and low EI. Compared with asthma patients with low EI, those with high EI were significantly older ( $P=0.046)$, had lower BMI $(P<0.001)$, were more likely to be male $(P<0.001)$, had higher pack-years of smoking $(P<0.001)$, and had a greater number of acute exacerbations per year $(P<0.001)$. More asthma patients with high EI were ULP $(34.4 \%)$ than those with low EI $(13.4 \%, P<0.001)$. Regarding PFTs, all asthma patients with high EI had airflow limitation, but only $64.05 \%$ of those with low EI had airflow limitation. The $\mathrm{FEV}_{1} \%$ predicted values and $\mathrm{FEV}_{1} / \mathrm{FVC} \%$ were significantly lower in asthma patients with high EI than those with low EI. There was no significant difference in VC $(P=0.133)$ or FVC ( $P=0.097)$ between these patients. These results show that the characteristics of asthma patients with high EI (severe and persistent airflow limitation, older age, more tobacco smoke exposure, and more upper-zone-predominant emphysema) were similar to those of COPD patients.

\section{Comparison of patients with COPD and asthma with high El}

We compared the clinical characteristics and emphysema measurements of patients with asthma having high EI with those with COPD (Table 4). Compared with COPD patients, asthma patients with high EI were younger $(P=0.025)$ and had more acute exacerbations per year $(P=0.012)$. There was no significant difference in sex $(P=0.494)$ or BMI $(P=0.918)$ between the groups. The FVC and VC of asthma patients with high EI were significantly higher than COPD patients, but there were no significant differences in FEV1.0\% predicted $(P>0.1)$ and FEV1.0/FVC $(P>0.1)$. Additionally, there was no significant difference in \%LAA-950 $(P=0.152)$ and per $\operatorname{ULP}(P=0.862)$ of the two groups. These results showed that asthma patients with high EI had similar clinical features (age, sex, BMI, airflow limitation, tobacco smoke exposure, and emphysema distribution) to COPD patients. 
Table 4 Characteristics of asthma patients with high El and COPD patients

\begin{tabular}{|c|c|c|c|}
\hline Characteristics & Asthma with high EI $(n=32)$ & COPD $(n=125)$ & $P$-value \\
\hline Age, years & $61.2 \pm 9.4$ & $65.8 \pm 9.3$ & $0.025^{a}$ \\
\hline Sex, female/male & $6 / 26$ & $32 / 93$ & $0.494^{\mathrm{b}}$ \\
\hline BMI, $\mathrm{kg} / \mathrm{m}^{2}$ & $22.5 \pm 3.2$ & $22.6 \pm 4.5$ & $0.918^{a}$ \\
\hline Smoking, pack-years & $29.8 \pm 30.0$ & $34.5 \pm 26.6$ & $0.224^{a}$ \\
\hline Current/former/never smoker & $11 / 12 / 9$ & $57 / 49 / 19$ & $0.207^{\mathrm{b}}$ \\
\hline Acute exacerbations & $\mathrm{I} .7 \pm \mathrm{I} . \mathrm{I}$ & $1.2 \pm 0.9$ & $0.012^{\mathrm{a}}$ \\
\hline \multicolumn{4}{|l|}{ Postbronchodilator } \\
\hline $\mathrm{FEV}_{1} \%$ predicted & $49.5 \pm 16.7$ & $44.3 \pm 18.6$ & $0.152^{\mathrm{a}}$ \\
\hline FVC\% predicted & $84.3 \pm 16.4$ & $73.6 \pm 17.5$ & $0.004^{\mathrm{a}}$ \\
\hline VC\% predicted & $85.9 \pm 15.9$ & $76.0 \pm 16.2$ & $0.002^{\mathrm{a}}$ \\
\hline $\mathrm{FEV}_{1} / \mathrm{FVC} \%$ & $47.9 \pm 10.6$ & $48.1 \pm 12.2$ & $0.862^{\mathrm{a}}$ \\
\hline \multicolumn{4}{|l|}{ Response to $\beta_{2}$-agonist } \\
\hline$\Delta \mathrm{FEV}_{\mathrm{l}}, \mathrm{L}$ & $0.334 \pm 0.158$ & $0.143 \pm 0.009$ & $<0.00 \mathrm{I}^{\mathrm{a}}$ \\
\hline$\%$ change in $\mathrm{FEV}_{1} \%$ & $31.2 \pm 19.8$ & $15.2 \pm 12.8$ & $<0.00 \mathrm{I}^{\mathrm{a}}$ \\
\hline$\%$ LAA-950, \% & $17.1 \pm 6.3$ & $15.8 \pm 11.9$ & $0.105^{\mathrm{a}}$ \\
\hline Per ULP, n (\%) & II (34.4) & $61(48.8)$ & $0.144^{b}$ \\
\hline
\end{tabular}

Notes: Data are presented as mean \pm SD. ${ }^{a}$ Analysis of Mann-Whitney $U$ test. ${ }^{b}$ Analysis of chi-square test.

Abbreviations: $\mathrm{BMI}$, body mass index; El, emphysema index; $\triangle \mathrm{FEV}$, increases in forced expiratory volume in I second; FEV , forced expiratory volume in I second; FVC, forced vital capacity; \%LAA-950, percentage of lung voxels with CT attenuation value below -950 HU; SD, standard deviation; ULP, upper-lung-zone predominance; VC, vital capacity.

\section{Predictors of high El in asthma patients}

Six variables were included in a logistic regression model: age (per decade), sex, BMI, pack-years of smoking (per 10 pack-years), FEV1\% predicted (per 10\% decrease), and acute exacerbations. Using the stepwise method, age and sex were not found to be associated with the presence of high EI in asthma patients $(P>0.05)$. As shown in Table 5, packyears of smoking (odds ratio [OR] $=1.405, P=0.003$ ), acute exacerbations ( $\mathrm{OR}=2.72, P=0.005)$, and $\mathrm{FEV} 1 \%$ predicted decrease $(\mathrm{OR}=1.428, P=0.013)$ are positive predictive factors of asthma patients with high EI. The presence of high EI was less likely in asthma patients with high BMI.

\section{Discussion}

In the present study, COPD patients had a higher extent of emphysema on quantitative CT than asthma patients or controls. The normal range of \%LAA-950 in Chinese aged

Table 5 Multivariate logistic regression for predictors of high El among asthma patients

\begin{tabular}{llll}
\hline Variable & OR & 95\% Cl & P-value \\
\hline $\begin{array}{l}\text { Pack-years of smoking } \\
\text { (per 10 pack-years) }\end{array}$ & 1.405 & $1.13-1.75$ & 0.003 \\
BMI, kg/m & & & \\
Acute exacerbations & 0.738 & $0.63-0.87$ & $<0.001$ \\
FEV \% predicted & 2.720 & $1.36-5.4$ & 0.005 \\
(per 10\% decrease) & 1.428 & $1.08-1.89$ & 0.013 \\
\hline
\end{tabular}

Abbreviations: El, emphysema index; $\mathrm{BMI}$, body mass index; $\mathrm{Cl}$, confidence interval; $\mathrm{FEV}_{1}$, forced expiratory volume in I second; OR, odds ratio.
$>40$ years was $2.79 \% \pm 2.37 \%$. Compared with asthma patients with low EI, those with high EI were significantly older, more likely to be male, had higher pack-years of smoking, had more acute exacerbations, had more upper-zone-predominant emphysema, and had greater airflow limitation. Compared with COPD patients, asthma patients with high EI were younger and had more frequent acute exacerbations. There was no significant difference in sex ratios, pack-years smoking, FEV1.0/FVC, EI, or emphysema distribution between asthma patients with high EI and those with COPD.

Although the concept of ACOS is widely accepted, little is known about its diagnosis and treatment. To date, there is no blood test or other method of assessment that provides simple criteria for the diagnosis of ACOS. Asthma and COPD have different pulmonary function manifestations, airway inflammation types, and lung structure changes. Functional and inflammatory biomarkers, including BD test and eosinophilia in sputum, were recommended as part of the diagnostic criteria of ACOS in the Spanish COPD and GOLD guidelines. ${ }^{4,26}$ However, the measurements of lung structural changes have not been included in the current guidelines. As per our knowledge, this is the first study that has focused on the value of quantitative CT measurements of emphysema in the diagnosis of ACOS.

Emphysema measurements in quantitative $\mathrm{CT}$ are highly reproducible and correlate well with visual scoring systems and pathology measurements. ${ }^{13,27,28}$ In addition, emphysema assessment by quantitative $\mathrm{CT}$ is related to a decline in lung 
function, and mortality in COPD patients. ${ }^{29,30}$ Quantitative CT can also quantify large airway dimensions in chronic airway disease. However, previous studies show that the current quantitative CT technologies may overestimate the airway wall thickness. ${ }^{31,32}$ Additionally, small airways (diameter $<2 \mathrm{~mm}$ ), which play a critical role in the pathogenesis of asthma and COPD, cannot be depicted by HRCT because their thin walls are below the resolving power of HRCT. ${ }^{32,33}$ Therefore, airway dimensions were not measured in this study.

Until now, only a few studies have focused on the normal range of quantitative CT measurements of emphysema in the Chinese population. In this study, \%LAA-950 of controls aged $>40$ years was $2.79 \% \pm 2.37 \%$ compared with $2.0 \% \pm 2.7 \%$ in the COPDGene study. ${ }^{34}$ The COPDGene study suggested that \%LAA-950 was higher in males than females in healthy nonsmoking adults. ${ }^{34}$ However, such a difference was not noted in the present study. This may be due to differences in the race of study populations. In addition, the scanner models and different quantitative CT softwares may also influence the emphysema measurements.

Significantly higher quantitative CT emphysema parameters were found in COPD patients compared with patients with asthma and controls. This is consistent with the presence of emphysematous destruction in COPD patients. Besides the difference in the severity of emphysema, the emphysema distribution is also significantly different in COPD and asthma patients. More COPD patients are ULP than asthma patients, which is consistent with the fact that emphysema is more likely to involve the upper lung lobes in COPD..$^{35}$ These results suggest that extent and distribution of emphysema measured by quantitative CT may contribute to the differential diagnosis of COPD and asthma.

Using the cutoff point of \%LAA- $950=9.9 \%, 21.2 \%$ of asthma patients aged $>40$ years were noted to have high EI, indicating the presence of emphysema. Compared with asthma patients with low EI, those with high EI had higher pack-years of smoking. Using logistic regression method, pack-years of smoking (per 10 pack-years), acute exacerbations, $\mathrm{FEV}_{1} \%$ predicted (per $10 \%$ decrease), and BMI were associated with high EI among asthma patients. Repeated smoke-induced injury and repair could lead to alveolar wall destruction and apoptosis of epithelial and endothelial cells, thereby causing emphysema. ${ }^{36}$ These results suggest that some asthma patients may develop emphysematous lung destruction because of the exposure to toxic gases and particles. The underlying mechanisms and potential clinical impact of emphysema in asthma patients need further investigation.
Compared with asthma patients with low EI, those with high EI were older, more likely to be male, and had more severe airflow limitation. These results are consistent with the findings of a previous study demonstrating that asthma patients with emphysema were significantly older and more likely to be male than those without emphysema. ${ }^{37}$ The greater airflow limitation may be due to loss of lung tissue elasticity and small airway collapse during exhalation caused by emphysema. There were no significant differences in sex, smoking history, extent of airflow limitation, and EI between asthma patients with high EI and those with COPD. These results suggest that some patients with asthma have high EI on quantitative CT. Asthma patients with high EI have pathological (high extent of emphysema, more upper-predominant-emphysema) and clinical features (old age, smoking history, severe airflow limitation) similar to COPD patients, suggesting ACOS. These asthma patients fulfill the characteristics of ACOS described in the GINA and GOLD guidelines. ${ }^{4}$ Therefore, quantitative CT measurements of emphysema may be useful in the diagnosis of ACOS.

There was no significant difference in $\triangle \mathrm{FEV}_{1}$ in bronchial dilation test between asthma patients with high and low EI, but the percentage of $\triangle F E V_{1}$ was significantly higher in those with high EI. One possible explanation for this is that the baseline FEV1.0 is lower in asthma patients with high EI. The $\Delta \mathrm{FEV}_{1}$ were significantly higher in asthma patients with high EI than COPD patients. A previous study demonstrated that ACOS patients have greater response to BDs than COPD patients. ${ }^{38}$ This result suggests that bronchial dilation test may help in distinguishing ACOS from COPD patients.

Previous studies have shown that ACOS patients have a greater number of acute exacerbations than those with COPD or asthma alone. ${ }^{5,6}$ In this study, a greater number of acute exacerbations were found in asthma patients with high EI compared with those with asthma and low EI or COPD. Frequent exacerbations are strongly associated with long-term morbidity and mortality in asthma and COPD..$^{39}$ These findings would suggest that management of asthma patients with high EI should be directed toward exacerbation prevention.

Quantitative CT is a promising technique in the diagnosis and evaluation of chronic airway diseases. Although quantitative CT allows repeated, noninvasive evaluation of emphysema, the measurement of emphysema can be influenced by many factors, including image reconstruction algorithm, section thickness, inspiration level, radiation dose, and scanner/ study center. ${ }^{16}$ There are still no widely accepted standards 
for the evaluation of emphysema in quantitative CT. More research is needed before the application of quantitative $\mathrm{CT}$ in clinical practice.

\section{Limitations}

Our study had several limitations. First, this is a crosssectional study and therefore we were not able to study clinical outcomes of the participants. Second, this study was conducted at a single institute. Third, we had a small sample size. Further prospective studies involving multicenter and large sample size of patients are needed.

\section{Conclusion}

Some asthma patients have high EI on quantitative CT with clinical features (age, tobacco smoking, extent of airflow limitation, extent, and distribution of emphysema) similar to those of COPD. These patients had more frequent acute exacerbations than asthma patients with low EI and those with COPD. The clinical features of asthma patients with high EI fulfill the characteristics of ACOS described in the GINA and GOLD guidelines. ${ }^{4}$ Quantitative CT measurements of emphysema, therefore, may help diagnose ACOS.

\section{Disclosure}

The authors report no conflicts of interest in this work.

\section{References}

1. Bateman ED, Hurd SS, Barnes PJ, et al. Global strategy for asthma management and prevention: GINA executive summary. Eur Respir J. 2008;31(1):143-178.

2. Vestbo J, Hurd S, Agustí AG, et al. Global strategy for the diagnosis, management, and prevention of chronic obstructive pulmonary disease. Am J Respir Crit Care Med. 2013;187(4):347-365.

3. Papaiwannou A, Zarogoulidis P, Porpodis K, et al. Asthma-chronic obstructive pulmonary disease overlap syndrome (ACOS): current literature review. J Thorac Dis. 2014;6(Suppl 1):S146-S151.

4. Global Initiative for Asthma and Global Initiative for Chronic Obstructive Lung Disease. Asthma COPD and Asthma-COPD Overlap Syndrome (ACOS); 2015. Available from: http://www.ginasthma.org/local/ uploads/files/AsthmaCOPDOverlap.pdf. Accessed June 11, 2015.

5. Ulrik CS, Nielsen M, Bårnes CB. Clinical characteristics of the asthmaCOPD overlap syndrome - a systematic review. Int J Chron Obstruct Pulmon Dis. 2015;10:1443-1454.

6. Menezes AM, Montes DOM, Perez-Padilla R, et al. Increased risk of exacerbation and hospitalization in subjects with an overlap phenotype: COPD-asthma. Chest. 2014;145(2):297-304.

7. Andersen H, Lampela P, Nevanlinna A, Saynajakangas O, Keistinen T. High hospital burden in overlap syndrome of asthma and COPD. Clin Respir J. 2013;7(4):342-346.

8. Gibson PG, Simpson JL. The overlap syndrome of asthma and COPD: what are its features and how important is it? Thorax. 2009;64(8): 728-735.

9. Hogg JC, Timens W. The pathology of chronic obstructive pulmonary disease. Annu Rev Pathol. 2009;4:435-459.

10. Abramson M, Perret J, Dharmage S, McDonald V, McDonald C. Distinguishing adult-onset asthma from COPD: a review and a new approach. Int J Chron Obstruct Pulmon Dis. 2014;9:945-962.
11. Hong KY, Lee JH, Park SW, et al. Evaluation of emphysema in patients with asthma using high-resolution CT. Korean J Intern Med. 2002; 17(1):24-30.

12. Gelb AF, Yamamoto A, Mauad T, Kollin J, Schein MJ, Nadel JA. Unsuspected mild emphysema in nonsmoking patients with chronic asthma with persistent airway obstruction. J Allergy Clin Immunol. 2014;133(1): 263-265.

13. Van Tho N, Wada H, Ogawa E, Nakano Y. Recent findings in chronic obstructive pulmonary disease by using quantitative computed tomography. Respir Investig. 2012;50(3):78-87.

14. Fei G, Tu Y, Zhang Y. The COPD assessment test correlates well with the computed tomography measurements in COPD patients in China. Int J Chron Obstruct Pulmon Dis. 2015;10:507-514.

15. Madani A, Zanen J, de Maertelaer V, Gevenois PA. Pulmonary emphysema: objective quantification at multi-detector row CT - comparison with macroscopic and microscopic morphometry. Radiology. 2006;238(3):1036-1043.

16. Mets OM, de Jong PA, van Ginneken B, Gietema HA, Lammers JWJ. Quantitative computed tomography in COPD: possibilities and limitations. Lung. 2012;190(2):133-145.

17. Global Initiative for Asthma (GINA). Global Strategy for Asthma Management and Prevention; 2015. Available from: http://www. ginasthma.org/local/uploads/files/GINA_Pocket_2015.pdf. Accessed July 5, 2015.

18. Global Initiative for Chronic Obstructive Lung Disease (GOLD). Global Strategy for the Diagnosis, Management and Prevention of COPD; 2015. Available from: http://www.goldcopd.org/. Accessed July 5, 2015.

19. Laszlo G. Standardisation of lung function testing: helpful guidance from the ATS/ERS Task Force. Thorax. 2006;61(9):744-746.

20. Heussel CP, Herth FJF, Kappes J, et al. Fully automatic quantitative assessment of emphysema in computed tomography: comparison with pulmonary function testing and normal values. Eur Radiol. 2009;19(10): 2391-2402.

21. Gevenois PA, de Maertelaer V, De Vuyst P, Zanen J, Yernault JC. Comparison of computed density and macroscopic morphometry in pulmonary emphysema. Am J Respir Crit Care Med. 1995;152(2):653-657.

22. Gevenois PA, De Vuyst P, de Maertelaer V, et al. Comparison of computed density and microscopic morphometry in pulmonary emphysema. Am J Respir Crit Care Med. 1996;154(1):187-192.

23. Parr DG, Stoel BC, Stolk J, Stockley RA. Pattern of emphysema distribution in alpha1-antitrypsin deficiency influences lung function impairment. Am J Resp Crit Care. 2004;170(11):1172-1178.

24. Gao Y, Zhai X, Li K, et al. Asthma COPD overlap syndrome on CT densitometry: a distinct phenotype from COPD. COPD. Epub $2016 \mathrm{Jan}$ 8:1-6.

25. Hersh CP, Make BJ, Lynch DA, et al. Non-emphysematous chronic obstructive pulmonary disease is associated with diabetes mellitus. BMC Pulm Med. 2014;14:164.

26. Miravitlles M, Soler-Cataluña JJ, Calle M, et al. Spanish COPD guidelines (GesEPOC): pharmacological treatment of stable COPD. Arch Bronconeumol. 2012;48(7):247-257.

27. Gierada DS, Yusen RD, Pilgram TK, et al. Repeatability of quantitative CT indexes of emphysema in patients evaluated for lung volume reduction surgery. Radiology. 2001;220(2):448-454.

28. Bakker ME, Stolk J, Putter H, et al. Variability in densitometric assessment of pulmonary emphysema with computed tomography. Invest Radiol. 2005;40(12):777-783.

29. Mohamed HF, de Hoop B, Zanen P, et al. CT-quantified emphysema in male heavy smokers: association with lung function decline. Thorax. 2011;66(9):782-787.

30. Haruna A, Muro S, Nakano Y, et al. CT scan findings of emphysema predict mortality in COPD. Chest. 2010;138(3):635-640.

31. King GG, Muller NL, Pare PD. Evaluation of airways in obstructive pulmonary disease using high-resolution computed tomography. Am J Respir Crit Care Med. 1999;159(3):992-1004.

32. Conradi SH, Lutey BA, Atkinson JJ, Wang W, Senior RM, Gierada DS. Measuring small airways in transverse CT images. Acad Radiol. 2010;17(12):1525-1534. 
33. Konstantinos Katsoulis K, Kostikas K, Kontakiotis T. Techniques for assessing small airways function: possible applications in asthma and COPD. Resp Med. Epub 2013 Jun 10.

34. Zach JA, Newell JD, Schroeder J, et al. Quantitative computed tomography of the lungs and airways in healthy nonsmoking adults. Invest Radiol. 2012;47(10):596-602.

35. Bastos HN, Neves I, Redondo M, et al. Influence of emphysema distribution on pulmonary function parameters in COPD patients. J Bras Pneumol. 2015;41(6):489-495.

36. Mitsunobu F, Ashida K, Hosaki Y, et al. Influence of long-term cigarette smoking on immunoglobulin E-mediated allergy, pulmonary function, and high-resolution computed tomography lung densitometry in elderly patients with asthma. Clin Exp Allergy. 2004;34(1):59-64.
37. Mochizuki T, Nakajima H, Kokubu F, Kushihashi T, Adachi M. Evaluation of emphysema in patients with reversible airway obstruction using high-resolution CT. Chest. 1997;112(6):1522-1526.

38. Suzuki T, Tada Y, Kawata N, et al. Clinical, physiological, and radiological features of asthma-chronic obstructive pulmonary disease overlap syndrome. Int J Chron Obstruct Pulmon Dis. 2015;10:947.

39. Leuppi JD, Ott SR. Management von Exazerbationen in asthma und COPD. Ther Umsch. 2014;71(5):289-293.

International Journal of COPD

\section{Publish your work in this journal}

The International Journal of COPD is an international, peer-reviewed journal of therapeutics and pharmacology focusing on concise rapid reporting of clinical studies and reviews in COPD. Special focus is given to the pathophysiological processes underlying the disease, intervention programs, patient focused education, and self management protocols.

\section{Dovepress}

This journal is indexed on PubMed Central, MedLine and CAS. The manuscript management system is completely online and includes a very quick and fair peer-review system, which is all easy to use. Visit http://www.dovepress.com/testimonials.php to read real quotes from published authors.

Submit your manuscript here: http://www.dovepress.com/international-journal-of-chronic-obstructive-pulmonary-disease-journal 